\title{
Gaps in HIV testing: results from an audit of abortion services in England
}

Reducing undiagnosed and late diagnosed HIV infection in the population remains a public health priority. By the end of 2012, of the estimated 98400 people living with HIV in the UK, approximately 1 in $3(31700)$ were women of whom about 1 in 4 (7700) were unaware of their infection. ${ }^{1}$

There were 842200 conceptions for women aged 15-44 years in England in 2012; of these, 1 in $5(21 \%)$ resulted in abortions. ${ }^{2}$ Over 1 in 6 of all abortions carried out in England were conducted in non-National Health Service (NHS) settings in 2012. ${ }^{3}$

Unlinked anonymous surveys last conducted in 2004 identified an HIV prevalence of $1.19 \%$ among women attending NHS abortion services in London compared to $0.57 \%$ in corresponding antenatal clincs. ${ }^{4}$ In 2008, the British HIV Association (BHIVA) recommended universal offer of testing for women attending abortion services in their National Guidelines for HIV Testing. ${ }^{5}$ Guidelines from the National Institute for Health and Care Excellence (NICE) and the Royal College of Obstetricians and 
Gynaecologists (RCOG), both published in 2011, support the offer of a test to all women attending abortion services in accordance with the BHIVA guidelines. ${ }^{6}$

${ }^{7}$ RCOG guidelines state that an abortion service provider must have an HIV testing policy in place. $^{7}$

Despite the guidelines, little is known about the extent and patterns of HIV testing in abortion services in England. The RCOG has called for additional research into the epidemiology of HIV and better auditing standards in HIV testing among women being seen for abortions. ${ }^{7}$ In June 2013, Public Health England (PHE) conducted an audit, asking abortion service providers about their policies and practices around HIV testing for women attending their services.

A randomly selected sample of 140 abortion service providers in England, 131/244 eligible NHS trusts and 9/15 approved non-NHS providers, were chosen as sampling sites. Of the nine non-NHS providers, only four took part in the audit. Gynaecology clinical leads from each provider were invited by e-mail to complete a 27 -item secure and anonymous online questionnaire hosted by PHE's SelectSurvey.Net.

Despite a disappointingly low response rate of $28 \%(39 / 140)$ we were able to make a number of observations about the delivery of HIV testing in these settings, which varied considerably and was influenced by different factors. A number of abortion service providers was not following recommended guidelines. Testing was largely dependent on whether a clinic had an HIV testing policy, of which only about two-fifths $(38 \%, 15 / 39)$ had. Around

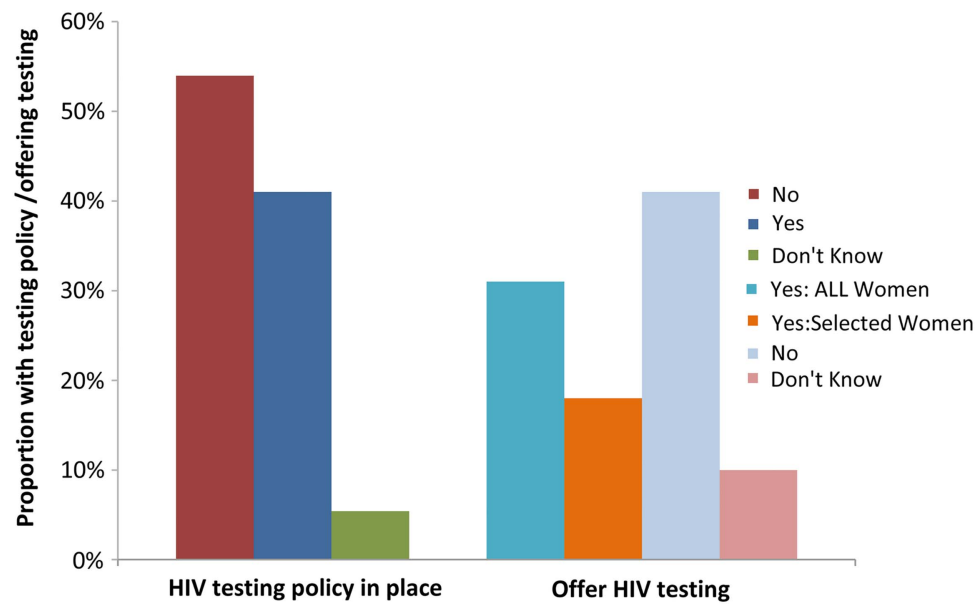

Figure 1 Proportion of abortion service providers in England with a testing policy and those offering HIV testing in abortion clinics in $2012(n=39)$. half $(54 \%)$ of the survey respondents did not have a testing policy; and of those that had a policy (16/39), one provider did not test.

Some (18/39) providers were offering some form of HIV testing: either as opt-out routine testing to all women or to women selected based on perceived HIV-related risks. Of the providers (23/ 39) who either did not have or did not know if their clinic had a testing policy, more than 1 in 10 (3/23) were providing HIV testing (Figure 1).

Responses from non-NHS providers revealed that HIV testing in this sector was dependent on commissioning service specifications that were agreed with local authorities.

These data show that there are gaps in the provision of HIV testing for women attending abortion services, and either absent or inadequate policies and practices. Opportunities are being missed to diagnose HIV infections promptly and reduce the number of undiagnosed infections.

PHE is developing a programme of work to investigate the inadequacies in HIV testing in these settings, and to address the barriers to commissioning services that promote HIV testing in this sector.

\section{Merrington Omakalwala, * MSC}

Research Assistant/Information Analyst, Centre for Infectious Disease Surveillance and Control, Public Health England, London, UK;

merrington.omakalwala@phe.gov.uk

\section{Louise Logan, MSC}

Senior Scientist (Epidemiology), Centre for Infectious Disease Surveillance and Control, Public Health England, London, UK; Louise.Logan@phe.gov.uk
Livingstone Musoro, PhD

Senior Lecturer (Health Studies), Faculty of Social Sciences and Humanities, Metropolitan University, London, UK; L.Musoro@londonmet.ac.uk

\section{Fortune Ncube, MBBS, FFPH}

Consultant Epidemiologist (Public Health Medicine/ Blood Bourne Viruses), Centre for Infectious Disease Surveillance and Control, Public Health England, London, UK; fortune.ncube@phe.gov.uk

*Corresponding author.

Competing interests None.

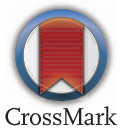

J Fam Plann Reprod Health Care 2014;40:315-316. doi:10.1136/jprhc-2014-101057

\section{REFERENCES}

1 Aghaizu A, Brown EA, Nardone A, et al.; and contributors. HIV in the United Kingdom: 2013 Report: data to end 2012. London: Public Health England, November 2013. http://www. hpa.org.uk/webc/HPAwebFile/HPAweb_C/ 1317140300680 [accessed 4 July 2014].

2 Office for National Statistics. Conceptions in England and Wales, 2012. 25 February 2014. http://www.ons.gov.uk/ons/dcp 171778_353922.pdf [accessed 5 July 2014].

3 Department of Health. Abortion Statistics, England and Wales: 2013. Summary information from the abortion notification forms returned to the Chief Medical Officers of England and Wales. https://www.gov.uk/ government/uploads/system/uploads/ attachment_data/file/307650/Abortion statistics_England_and_Wales.pdf [accessed 5 July 2014]

4 Unpublished report from the Health Protection Agency and Health Protection Scotland. Supplementary data tables of the unlinked anonymous prevalence surveys of pregnant women: data to the end of 2004. Surveillance update 2005.

5 British HIV Association (BHIVA), British Association of Sexual Health (BASHH) and HIV \& British Infection Society (BIS). UK National Guidelines for HIV Testing 2008. September 2008. http://www.bhiva.org/HIV Testing2008.aspx [accessed 2 October 2013].

6 National Institute for Health and Care Excellence (NICE). Increasing the Uptake of HIV Testing Among Black Africans in England. (Clinical Guidance No. 33). 2011. http://www. nice.org.uk/guidance/ph33 [accessed 2 October 2013].

7 Royal College of Obstetricians and Gynaecologists (RCOG). The Care of Women Requesting Induced Abortion. (Evidence-based Clinical Guideline No. 7). November 2011. http://www.rcog.org.uk/womens-health/ clinical-guidance/care-women-requestinginduced-abortion [accessed 2 October 2013]. 